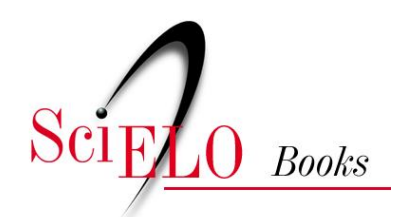

\title{
Dos palabras sobre pedagogía y humanismo moderno
}

\author{
Roberto Johann Briones Yela
}

\section{SciELO Books / SciELO Livros / SciELO Libros}

BRIONES YELA, R.J. Dos palabras sobre pedagogía y humanismo moderno. In: IZA VILLACÍS, V.A., ed. Persona, educación y filosofía: reflexiones desde la educación universitaria [online]. Quito: Editorial Abya-Yala, 2018, pp. 155-165. ISBN: 978-9978-10-493-4. https://doi.org/10.7476/9789978104934.0010.

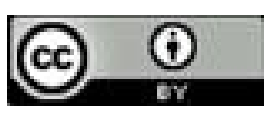

All the contents of this work, except where otherwise noted, is licensed under a Creative Commons Attribution 4.0 $\underline{\text { International license. }}$

Todo o conteúdo deste trabalho, exceto quando houver ressalva, é publicado sob a licença Creative Commons Atribição 4.0.

Todo el contenido de esta obra, excepto donde se indique lo contrario, está bajo licencia de la licencia $\underline{\text { Creative }}$ Commons Reconocimento 4.0. 


\title{
Dos palabras sobre pedagogía y humanismo moderno
}

\author{
Roberto Johann Briones Yela ${ }^{1}$
}

Filósofo es aquel que sabe lo que tiene que pensar

(Sócrates)

\section{Resumen}

El presente trabajo, no busca generar mayores discusiones al respecto de la comprensión que se tiene hoy de pedagogía, sino más bien, pretende despertar en el lector un momento de reflexión profunda desde su recordar lo que entendimos por aprendizaje y/o formación y lo que realmente implica descubrir esas categorías.

Desde aquí, brevemente se muestran algunas ideologías pedagógicas, cerrando la meditación pedagógica con aportes desde la filosofía frente al momento a-histórico del hombre del siglo XX.

Palabras clave: Pedagogía, María Zambrano, ser humano, filosofía.

1 Magister en Educación, mención Gerencia; Magister en Filosofía por la Universidad Pontificia Bolivariana, Medellín, Colombia Candidato a Doctorando en Filosofía UPB - Medellín, Colombia Docente Pastoral Universitaria, Universidad Politécnica Salesiana, Sede Guayaquil. 
156

\section{Abstract}

This work does not seek to generate further discussion regarding the understanding that is today's pedagogy, but rather, seeks to awaken in the reader a moment of deep reflection since his recall what they understood by learning or training and what actually involves to discover those categories.

From here briefly are some ideologies pedagogical, closing educational meditation with contributions from philosophy against the a-historical moment of 20th-century man.

Keywords: Pedagogy, María Zambrano, human, philosophy.

\section{Introducción}

Al hablar de pedagogía hoy, vienen a nuestra mente los recuerdos de aquellas cosas que los maestros intentaron hacer para que podamos "entender" y "aprender" las diferentes categorías del conocimiento formal y científico. Lo hayan logrado o no; en el estudiante lo que quedaba era la idea de que la pedagogía era "algo" que servía para que las personas lograran meter en su cabeza los conocimientos que luego servirían para una vida exitosa y perfecta. Si en realidad dichas categorías luego servían o no para la vida práctica, aún no queda claro; pero lo cierto es que la gran mayoría de docentes, generalmente pregonaban que su materia "era la más importante para la vida..."

Lejos están aquellas pretensiones de lo que realmente es la pedagogía sí; por ejemplo, tomamos literalmente la etimología del tér-

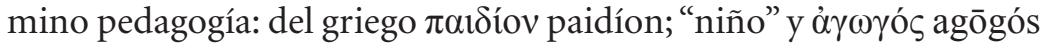
"guía, conductor".

Esta realidad, nos debería dejar sorprendidos si tomamos en cuenta que como seres racionales, lógicos y coherentes, entendiéramos que los docentes hoy (antes tal vez un poco), ni son guías ni conducen el aprendizaje por/hacia caminos específicos. Esto, básicamente porque no 
se entiende —-tampoco—, cuál es ese "camino" que se le debe hacer recorrer al estudiante y en el cual, el docente, debería ser guía o conductor.

En nuestra sociedad, por ejemplo; y para entender el sentido de lo que es una competencia relacionada con la pedagogía, Santos de Souza (2000) nos aproxima; a través de cinco elementos fundamentales, a dicho conceptos desde necesidades sociales específicas:

- Los procesos de producción impuestos por las necesidades de la vida social;

- Los procesos de reproducción del conocimiento de una generación a otra;

- Los contextos sociales y culturales (clases y reglas de la vida social);

- Las imposiciones que ordenan y forman la vida social; y

- Las representaciones o modelos de pensamiento acerca del mundo y de las cosas (de Souza, 2000).

Aquí vamos encontrando "el camino" que, desde la visión de mundo, se pretende hacer seguir a la pedagogía: ir hacia aquello que la sociedad le impone como visión social correcta.

En ninguno de los puntos señalados por de Souza, encontramos la búsqueda del ser, el desarrollo de sus capacidades racionales, el sentido de la vida o el encuentro con el otro; sino solo y únicamente, los mandamientos de la sociedad para sustentar el/los modelos modernos que heredamos desde la industrialización.

En la academia, se busca revertir esta situación, desde el planteamiento de fundamentos pedagógicos como los de la pedagogía crítica; ${ }^{2}$ propuesta de enseñanza que según el americano Henry Giroux (2009), ayuda a los estudiantes a cuestionar además de desafiar la dominación, las creencias y prácticas que la generan; el constructivismo, corriente pedagógica sostenida por el suizo Jean Piaget (1957) entre otros, que se basa en la teoría del conocimiento constructivista y que

2 La pedagogía crítica, es sobre todo una praxis política y ética que implica reconocer que estas sustentan las prácticas educativas (Ayuste, 1997). 
postula la necesidad de entregar al alumno herramientas que le permitan crear sus propios procedimientos para resolver una situación problémica y finalmente, el aprendizaje cooperativo de Ty Panitz (2009), que trata de organizar las actividades dentro del aula para convertirlas en una experiencia social y académica de aprendizaje.

A este desafío - revertir la situación monopolizadora y esclavista en que ha caído la pedagogía hoy en día-, se busca responder desde estrategias filosóficas y pedagógicas que permitan entender por “formación", no solo aquello que posibilite una profesión, sino aquello que requiera una extensión, un plus, que abarque la búsqueda de la verdad y la apropiación de la sabiduría en un mundo aquejado de respuesta ante los retos irrenunciables que impone la sociedad.

La formación valorativa, implica una dimensión cognitiva, una socio-afectiva y otra práxica. La primera está ligada con la comprensión y el análisis, al tiempo que la segunda se vincula con los sentimientos, afectos y actitudes; y la última, está relacionada con las prácticas valorativas y actitudinales de los sujetos. Una adecuada formación valorativa, exige un trabajo en cada una de las dimensiones, ya que no basta con formar individuos con mejor competencia para el análisis valorativo, ni solo despertar sentimientos y actitudes, ni solo modificar los actos. Se trata de formar seres más libres, más éticos, más autónomos, más interesados, más solidarios y más comprometidos consigo mismos y con los demás; seres más integrales (de Zubiría, 2010, p. 25).

Julián de Zubiría, define un modelo pedagógico como

...aquel que responde a las preguntas fundamentales: ¿Para qué enseñar? (propósitos), ¿qué enseñar? (contenidos), ¿cuándo enseñar? (secuencia), ¿cómo enseñar? (estrategia metodológica) y ¿qué, cómo y cuándo evaluar? (evaluación); y deduce de la concepción ${\operatorname{de~} \mathrm{Not}^{3}}^{3}$ (2001) que, además de los modelos hetero-estructurante y

3 Desde el enfoque pedagógico, Louis Not ha propuesto una relación profesor-estudiante centrada en el diálogo, modelo que ha denominado Enseñanza Dialogante. Señala que el modelo de educación más clásica se ha dedicado a una enseñanza en tercera persona, en la cual el alumno se asemeja a un 
auto-estructurante, puede existir una síntesis a nivel dialéctico entre los dos: el modelo inter-estructurante (de Zubiría, 2010, p. 28).

De Zubiría, además afirma que:

Una Pedagogía Dialogante, ${ }^{4}$ debe plantear como fin último de la educación, el desarrollo del estudiante no del conocimiento; y su propósito central debe ser la interdependencia integral y escalonada de las tres dimensiones del ser humano: la dimensión cognitiva (ligada al pensamiento), la dimensión afectiva (ligada a los sentimientos) y la dimensión de la praxis (actuar mejor). El proceso pedagógico, entonces, debe garantizar la autonomía de cada una de las dimensiones, y a la vez; su interrelación y desarrollo paralelo y continuo (de Zubiría, 2010, p. 30).

La visión de este autor colombiano, es destacable porque devuelve la palabra al estudiante, no como sujeto de conocimiento — visión ya presentada por algunas ideologías pedagógicas—, sino como sujeto pensante capaz de generar procesos lógicos, racionales y coherentes, desde donde se gesta el proceso humanizante, orientado al desarrollo de las dimensiones ya presentadas.

A partir de aquí, se vuelve necesario dedicar un espacio a la descripción de aquello existente en cuanto a teorías pedagógicas de la era moderna.

objeto que se va formando a través de acciones que se ejercen sobre él y el educador, actúa como único sujeto activo, constituyéndose en el centro de iniciativas y gestión de las actividades educativas.

4 Pedagogía que plantea como fin último de la educación, el desarrollo del estudiante, no del conocimiento; y su propósito central, es la interdependencia integral y escalonada, de las tres dimensiones del ser humano: la dimensión cognitiva (ligada al pensamiento), la dimensión afectiva (ligada a los sentimientos) y la dimensión de la praxis (actuar mejor). Este proceso debe garantizar la autonomía de cada una de las dimensiones, y a la vez, su interrelación y desarrollo paralelo y continuo. 


\section{Paradigmas en la educación}

Desde qué categorías pedagógicas se educa, es un cuestionamiento válido a la hora de generar desafíos a la pedagogía. Por ello recorreremos brevemente los paradigmas que fundamentan los modelos pedagógicos implementados en nuestra época.

a) Paradigma conductual (J. Watson-B. Skinner): El modelo de enseñanza conductual, al acondicionar, facilita el aprendizaje. La enseñanza se orienta a conseguir un buen producto de aprendizaje, competitivo, medible y evaluable. En este entorno, el estudiante es una mera herramienta, cuyo fin es adaptarse a espacios determinados, restando la capacidad de crítica o de innovación.

\section{Cuadro 1}

Esquema pedagogía conductual

\begin{tabular}{|l|l|}
\hline Paradigma de investigación: & Proceso-producto. \\
\hline Modelo de profesor: & Competencial. \\
\hline Estudiante: & Receptor de conceptos y contenidos. \\
\hline Programación: & Por objetivos operativos. \\
\hline Enseñanza - aprendizaje: & Centrada en el producto. \\
\hline
\end{tabular}

Elaboración: Autor

b) Paradigma cognitivo (J. Bruner): Modelo que dispone de tres fases: pre-activa, activa y evaluativa. Implica un conjunto de procesos intelectuales básicos que pasan por la mente del profesor cuando organiza, dirige y desarrolla su comportamiento (pre-activa), interacción enseñanza - aprendizaje (activa) y retroactiva (evaluativa).

\section{Cuadro 2}

\section{Esquema pedagogía cognitiva}

\begin{tabular}{|l|l|}
\hline Paradigma de investigación: & Centrado en el profesor y el estudiante. \\
\hline Modelo de profesor: & Reflexivo y crítico; mediador, constructivista. \\
\hline Estudiante: & Procesador de información. \\
\hline Programación: & Por objetivos terminales. \\
\hline Enseñanza - aprendizaje: & Centrada en el proceso. \\
\hline
\end{tabular}

Elaboración: Autor 
c) Paradigma contextual (L. Shulman): Los fundamentos para la reforma de la enseñanza, se construyen sobre una idea que enfatiza la comprensión y el razonamiento, la transformación y la reflexión, el aprendizaje contextual y compartido como una de las principales manifestaciones de desarrollo de la persona. El profesor, los padres, la escuela, la comunidad se convierten de hecho en mediadores de la cultura contextualizada.

\section{Cuadro 3}

Esquema pedagogía contextual

\begin{tabular}{|l|l|}
\hline Paradigma de investigación: & Cualitativa y etnográfica. \\
\hline Modelo de profesor: & Técnico-crítico. \\
\hline Estudiante: & Constructor y experimentador. \\
\hline Programación: & $\begin{array}{l}\text { Transición entre plan de actuación y fase de realización. } \\
\text { (Negociación). }\end{array}$ \\
\hline Enseñanza - aprendizaje: & $\begin{array}{l}\text { Centrada en el ecosistema del estudiante, la clase, el } \\
\text { profesor, la escuela, la comunidad. }\end{array}$ \\
\hline
\end{tabular}

Elaboración: Autor

d) Paradigma socio-cognitivo (L. Vygotsky): La enseñanza como mediación en el aprendizaje y la cultura social, se orientan al desarrollo de capacidades, destrezas, valores y actitudes en contextos sociales concretos, interviniendo en procesos cognitivos y afectivo de entornos determinados.

Como podemos apreciar, según los modelos descritos y aplicados por la mayoría de instituciones educativas en Latinoamérica, se mantiene la visión de ser humano ligada a objetivos, entornos o visiones sociales, pero no a visiones humanas personalistas. ¿Por qué esto debe considerarse un problema?, pues porque debemos entendernos como seres humanos antes de intentar entender la naturaleza, la sociedad y el cosmos.

Este es uno de los problemas más radicales que atormentan al hombre de hoy, pues lejano del conocimiento de sí mismo, crece in- 
tentando alcanzar el éxito y la perfección según los paradigmas que esta sociedad le indica; aún si dicha "verdad", no llena o alcanza una visión real de felicidad.

\section{Cuadro 4}

\section{Esquema pedagogía socio-cognitiva}

\begin{tabular}{|l|l|}
\hline Paradigma de investigación: & Cualitativa, centrado en el profesor y el estudiante. \\
\hline Modelo de profesor: & $\begin{array}{l}\text { Posee una doble dimensión: mediador del aprendizaje y } \\
\text { de la cultura social e institucional. }\end{array}$ \\
\hline Estudiante: & $\begin{array}{l}\text { La persona producto de este modelo, será critica, cons- } \\
\text { tructiva y creadora con un saber disponible y el adecuado } \\
\text { manejo de herramientas para aprender utilizando lo } \\
\text { aprendido en la vida cotidiana y valorando la ciudadanía } \\
\text { como una actitud democrática y participativa. }\end{array}$ \\
\hline Programación: & $\begin{array}{l}\text { Los contenidos como formas de saber se articulan en el } \\
\text { diseño curricular de una manera constructiva y signi- } \\
\text { ficativa (arquitectura del conocimiento) y poseen una } \\
\text { relevancia social. }\end{array}$ \\
\hline Enseñanza-aprendizaje: & $\begin{array}{l}\text { La enseñanza debe subordinarse al aprendizaje, enten- } \\
\text { diéndose como medición y derivado de las teorías de } \\
\text { aprendizaje, tanto cognitivo como socializado. }\end{array}$ \\
\hline
\end{tabular}

Elaboración: Autor

Así nos lo presenta Byung-Chul Han, filósofo y ensayista surcoreano quien usa una muy simbólica comparación — sobre la situación de desesperación en la que se encuentra el ser humano-, cuando afirma que:

El mito de Prometeo puede reinterpretarse considerándolo una escena del aparato psíquico del sujeto de rendimiento contemporáneo, que se violenta a sí mismo, que está en guerra consigo mismo. En realidad, el sujeto de rendimiento, que se cree en libertad, se halla tan encadenado como Prometeo. El águila que devora su hígado en constante crecimiento es su álter ego, con el cual está en guerra. Así visto, la relación de Prometeo y el águila es una relación consigo mismo, una relación de auto-explotación. El dolor del hígado, que en sí es indoloro, es el cansancio. De esta manera, Prometeo, como sujeto de 
auto-explotación, se vuelve presa de un cansancio infinito. Es la figura originaria de la sociedad del cansancio. (Han, 2012, p. 59).

Estamos frente a una visión des-personalizante, que impregna al ser humano, débil, inseguro y lleno de miedos; haciéndolo esclavo de ideologías obtusas donde el centro es el tener (bienes, servicios, lujos, dinero), el poder (gobernar a las masas, dirigir desde caudillismos) y el placer (el hombre como objeto o recurso).

$\mathrm{Al}$ abordar lo que él llama "aparato psíquico del sujeto de rendimiento contemporáneo” (Han, 2012), el autor no hace otra cosa que recordarnos que vivimos en una época donde lo que cuenta para el hombre es la cantidad de dinero y poder que maneja, no cuánto ha logrado entender de su vida o si ha llegado al pleno conocimiento de su ser. A esto súmesele la idea de "auto-explotación” que impera en las personas, con el afán de alcanzar lo que la sociedad quiere que pensemos es progreso.

Por ella, la propuesta de Pedagogía Dialogante; presentada por De Zubiría, encuentra sentido desde que iniciamos ese autoconocimiento de quiénes somos realmente y; a la luz de dicha realidad, iniciamos un proceso de aceptación —en primera instancia—, y de evolución lógica en busca de entender que la pedagogía no es la búsqueda de metodologías sino el construirnos desde un camino que emprendemos bajo la guía de personas que únicamente, nos acompañarán en el recorrido que iniciamos en busca de la verdad.

Esto una pensadora española lo tenía claro: María Zambrano.

Pensadora, ensayista, pedagoga, pero sobretodo, filósofa; María Zambrano vivió siempre entre el compromiso político hacia su tierra, su visión educativa liberadora, el deseo de hacer de la filosofía una ciencia que lleve a la trascendencia y el pensamiento poético, fruto de la relación entre el hombre y lo divino.

De sus muchas experiencias de vida concluye que; si la filosofía es encontrarse con uno mismo y llegar a poseerse, la tarea de la educa- 
ción será alcanzar esa finalidad: una realidad trascendente, actualizando nuestra vida desde el universo del triduo sagrado-divino-humano.

Desde aquí se puede entender que, para María Zambrano, en la educación están las respuestas a los múltiples problemas que le toca enfrentar al hombre moderno.

Su visión de educación, no es aquella de carácter esclavista que conocemos y que la humanidad ha sufrido desde las primeras prácticas "educativas"; sino que Zambrano proyecta una visión fresca que parte del entender la vocación:

Todas las vocaciones tienen algo en común, sin duda alguna. El ahondar en ese luminoso fenómeno, exige todo un tratado, pero es más todavía un sistema de pensamiento desde el cual la vocación aparezca como algo inteligible; como uno de esos inteligibles que no solamente se entienden, sino que hacen entender. Y la mayor parte de las ideologías del mundo moderno, incluidos algunos sistemas filosóficos, no dejan lugar siquiera a que se tenga en cuenta el hecho de la vocación; es más, ni siquiera la palabra misma puede ser usada. (Sanchez Gey, 2011, p. 34).

En este entorno, resalta la figura de la vocación, misma que muchos autores (Buber, Mounier, Levinas, etcétera) relacionan con la visión del "otro" como sujeto de mi responsividad.

Sobre esto, Víctor Iza, quien está trabajando la visión ontológica levinasiana, afirma que:

No somos capaces de ser por nosotros mismos sin el otro, es el otro quien ha decidido en un momento dado de nuestra existencia por nosotros, -quien- decide al ver nuestro rostro y da respuesta, se 'responsiviza' en un acto de presencia, tal vez de amor, tal vez de responsabilidad (Iza, 2016, p. 12).

Con esto queda demostrado que el papel final de la pedagogía, va más allá de meras estrategias estructurales sobre el conocimiento y la ciencia, y que la debemos llevar a un nuevo grado de evolución: el pensar para ser antes que el educar para vivir. 


\section{Bibliografía}

Ayuste, A. (1997). Pedagogía crítica y modernidad. Cuadernos de pedagogía, $254,80-85$.

de Souza, S. (2000). eumed.net. Obtenido de Educación por competencias: tendencia global: https://goo.gl/9KTjaS

de Zubiría, J. (2010). Hacia una pedagogía dialogante. México: Asociación de Educadores de Latinoamérica y el Caribe.

Han, B. (2012). La sociedad del cansancio. Barcelona: Editorial Herder.

Iza, V. (2016). El olvido de la otredad en las relaciones económicas y el deterioro de la alteridad humana. En U. P. Salesiana, Desarrollo social y entornos empresariales en Ecuador (p. 220). Guayaquil: Abya-Yala.

Sánchez Gey, J. \& Casado, Á. (2011). María Zambrano, Filosofía y Educación: manuscritos. Barcelona: Editorial Club Universitario. 


\section{Área de Ciencias Sociales y del Comportamiento Humano}

Persona, Educación y Filosofía es un trabajo consciente, arduo y muy válido desde la perspectiva amplia de las ciencias. Humanismo, pedagogía y filosofía, se fusionan en una sola propuesta, donde el centro vuelve a los tiempos, a ser el Hombre. Desde la visión experiencial de los trabajos, hasta la cientificidad de los mismos, podemos darnos cuenta que este texto no es solo un trabajo académico, sino también una propuesta experiencial. La misma busca centrar al ser humano en una dimensión trascendental donde el trinomio razón-ciencia-fe se entrelaza efectiva y eficazmente para abordar la pérdida de sentido y de valores. Las visiones pedagógicas presentadas surcan el horizonte de lo novedoso, buscando aterrizar en tierra fértil, donde explayar su visión de mundo, de hombre y de persona. La visión ética, no puede faltar en este entramado, donde hoy pareciera que lo bueno puede ser malo y viceversa, perdiendo la identidad de vida y, por ende, el proyecto.
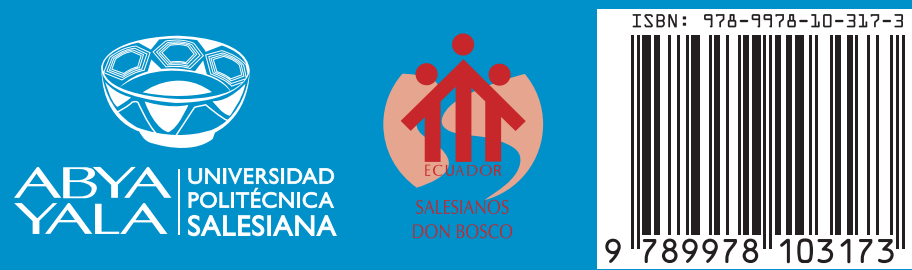